\section{AUTOMOBILE RESEARCH}

A CONSIDERABLE amount of the work at the A Research Laboratories of the Institution of Automobile Engineers is being done for Government departments, and since it is of a confidential nature may not be shown to a visitor. Nevertheless, at the recent inspection of the laboratories by members of the Automobile Research Committee and representatives of affiliated firms, there were several important investigations to be seen in actual operation. Usually, work of this nature arises directly out of the problems of the industry either in the form of an explicit question such as that of the fatigue strength of crankshafts, or from the more nebulous query as to whether aeration of the lubricant is a determining factor in the cause of bearing troubles, and these two cases are representative of the work being done at the Institution's Laboratory.

Three investigations into the aeration and frothing of lubricants were to be seen in operation on the above occasion. In the Chemical Laboratory, tests were being made to ascertain the frothing tendency of different oils at atmospheric pressure but variable temperature. In the Chassis Laboratory, a transparent bearing of plastic material has been arranged so that the behaviour of aerated oil can be observed, and it was of interest to note that, under the limited conditions permissible, the oil film at the pressure side was not ruptured. In the General Laboratory, a typical installation comprising a tank, aero-engine sump, oil cooler, pumps and filters has been set up in order to study the effect of high altitudes on the frothing occurring in an aircraft engine lubricating system. It is intended to run this at reduced pressures and to observe the amounts of froth formed in different parts of the system.

An investigation of a somewhat related character is that on the durability and wear of bearings, for which machines of two types have been developed. In these the test bearings are in the form of bushes cast or inserted in a steel shell and fitted as the big end of a connecting rod. As an extension of the work on these two machines, tests on full-size engine bearings are in prospect on another machine of special design by which an alternating load is applied by an external lever arrangement. This machine is in the experimental stage, and it was particularly interesting to observe the electric strain gauge developed for measuring the actual load applied to the bearing and the torsionmeter for the cyclic torque variation. Both measurements are made while the machine is in operation.

Fatigue tests on full-size crankshafts are carried on in machines which are arranged so that one throw alone is under test at a time, thus enabling a number of separate investigations to be carried out on one multi-throw shaft. The machines are of the constant-strain type, and the method of test involves the repeated application of a known deflexion to the crank under test. Piston-ring scuffing is being studied in a single-cylinder water-cooled engine, arranged so that the jacket temperature and quantity of lubricant supplied can be varied under control. A gas producer of the Government "Emergency" type is being used to supply gas to a converted petrol engine in an investigation to ascertain the power loss involved in the conversion, and the methods by which this loss can be made good.

In addition to such work as is described above, the Laboratory staff is actively engaged in the preparation and circulation of abstracts of current technical literature bearing on matters affecting the automobile industry. Inquiries for technical information are dealt with by the library staff; the library contains a valuable collection of text-books, period. icals, pamphlets, research reports and reference volumes, thus providing the basis for the information service which supplements the research work of the Committee.

\section{EARTHQUAKE ACTIVITY IN NEW ZEALAND}

A $\mathrm{N}$ earthquake of considerable intensity shook $A$ the southern part of the North Island of New Zealand at approximately 11.35 a.m. local time on August 2. The epicentre of the shock was considered in New Zealand to have been some fifty miles from Wellington. The country districts most affected were Manawatu and Wairarapa, where the damage was considerable, though not on the same scale as at Wellington. The shock was estimated to have been as severe as that on June 24 (NATURE, July 4, pp. 18-19) though, according to human perception, it was of shorter duration. During the June earthquake damage was done to post office and power lines and water supplies, and many buildings were cracked. During the August shock hundreds of chimneys fell, many windows were broken and several of the buildings damaged in June were so severely shaken that it is likely they will have to be demolished. Some streets were temporarily closed to traffic and the City Engineer estimated that the damage in Wellington may run into hundreds of thousands of pounds.

The Dominion Observatory at Wellington has just (1942) published Bulletin No. S-64, "The Seismicity of New Zealand", by R. C. Hayes, which divides the islands into four seismic zones having marked differences in seismicity. Bastings has stated that the seismicity of New Zealand as a whole is high compared with other countries, due mainly to the relatively large number of earthquakes of the semidestructive type. The seismicity of any region is governed by both the maximum intensity of the shocks which occur and the frequency of the earthquakes. In the work of Hayes, the relative seismicity is obtained by multiplying the average number of shocks per decade $(1835-1940)$ in the area of RossiForel intensity 10 by 10 , the average of intensity 9 by 2 , and adding these to the average number of intensity 8. Freeman's work had previously shown that earthquakes of R.F. intensity 9 are twice as destructive as those of intensity 8 , and those of intensity 10 are ten times as destructive as those of intensity 8.

The average number of earthquakes per year (1921-40) is considered separately. Whenever earthquake swarms such as that in the Taupo region in the latter half of 1922 occur, only the stronger ones have been considered. On these facts, the four regions are: (I) The northern half of South Island and the south-eastern half of North Island with Cook Strait in the centre. This has an average of 97.8 earthquakes per year, and a relative seismicity of 11.5 ; (II) the central portion of North Island, average $23 \cdot 0$ earthquakes per year and relative seismicity $1 \cdot 1$; (III) the whole of the southern half of South Island, average $12 \cdot 1$ per year and relative 